\title{
The Territorial Factor of Admission to a Regional University in the Context of the COVID-19 Pandemic (On the Example the Teacher Training Program)
}

\begin{abstract}
F. Kremen*, S. Kremen
Smolensk State University, Smolensk, Russia

*Corresponding author. Email: fmkremen@gmail.com

ABSTRACT

The territorial differences are seen as one of the reasons for unequal access to quality education. Students living in large cities have better opportunities for higher education than those living in small urban and rural settlements. The conditions of school graduations during the COVID-19 pandemic further exacerbate these differences. As a result of a survey and diagnostic test of 97 first-year undergraduate students at the Smolensk State University studying in the teacher training program, it was found that there are differences between students who came from the regional center and small settlements. A smaller number of the latter confirms the territorial inequality of higher education opportunities. However, these students have a higher motivation for the teaching profession, showed high activity in the implementation of their career plans, despite the difficulties of adapting to the educational process in the COVID-19 pandemic.
\end{abstract}

Keywords: Territorial factor, Students, Pedagogical Education, COVID-19 pandemic.

\section{INTRODUCTION}

The implementation of the accessibility of general education guaranteed by the Constitution of the Russian Federation (Article 43), in practice, faces a number of difficulties. Modern research [1] confirms the differentiation of Russian schools in terms of the quality of educational results, resources, and territorial features. In particular, average the Unified State Exam score of graduates is interrelated with such variables as socioeconomic characteristics of students and their families; material and human resources in schools; features of municipalities or territories where schools are located [2]. This differentiation of schools indicates that not all of them can perform their functions of a social elevator. Schoolchildren who receive education in small urban and rural settlements face such barriers to access to quality education as the peculiarities of settlement and transport accessibility, a lower level of socio-economic status of the population.

The regional context also manifests itself in the choice of educational trajectories after graduation. According to foreign and Russian researchers [3,4], geographical accessibility is an independent factor when choosing an educational institution. In Russia, higher education continues to be one of the most preferred career tracks among school graduates [5]. However, despite the wide coverage of the population with higher education, there is a great level of regional differentiation of its accessibility. Graduates of urban and rural schools do not have the same chances to enter a university. Applicants living in cities where universities are located have more advantages in admissions, bear the less financial burden and adapt more easily to new educational conditions. For families with low incomes living in territories remote from university cities, the choice of educational trajectories of their children is extremely limited [6]. Since most selective universities in Russia are concentrated in several regions, many graduates are initially focused on entering universities in their home region, not only based on the results of the Unified State Exam but also taking into account the material capabilities of families.

Applicants' choice of the field of study in regional universities is primarily due to the offer of educational programs, as well as the availability of budget places [7]. In recent years, there has been a steady trend of redistribution of state funding from socio-humanitarian areas of training, popular with applicants, to information (IT) and engineering. There is also sufficient budgetary 
funding for medical and pedagogical specialties. Over the past few years, there has been a significant increase in interest in teacher education on the part of applicants. The quality of admission to pedagogical universities in Russia is growing - the average score of applicants to these educational institutions has increased by four points over the past two years [8].

The popularity of pedagogical specialties in regional universities is due not only to the availability of budget places but also to the positive attitude of applicants and their parents to this profession. Schoolchildren involved in the educational process have been "learning" the teaching profession for years: they have a clear understanding of the subject, techniques, and results of work. At the same time, the personal and stylistic characteristics of teachers have a significant impact on the ideas about the meaning of pedagogical activity [9]. There is a direct connection between the positive experience of interaction with representatives of the teaching profession and the formed internal motivation for the work of a teacher [10]. Extensive employment opportunities in the specialty obtained are considered as an additional advantage for applicants from small urban and rural settlements.

In general, the process of professional selfdetermination of young people is influenced by a complex set of numerous conditions: various institutions of socialization, individual characteristics, and preferences, external situational factors, etc. The researchers note that the family has a significant influence on the choice of the educational trajectory of the graduate, including professional self-determination. In Russia, as a country more oriented towards traditional culture, the choice of profession is associated not so much with the desire of the individual himself, as with the active influence of the family or his social group [11]. Parents' opinions and advice turn out to be one of the most frequent and influential sources of information for choosing a future career [12].

The school, as a significant institution of socialization, also uses various practices aimed at developing students' professional self-determination. The most common in Russia includes specialized training, individual consultations, and recommendations on the choice of profession and level of education, activities aimed at familiarization with professions and educational institutions, etc. [13].

These directions are implemented differently in educational organizations, depending on their resource base. Thus, large schools have the opportunity to organize specialized training in more areas attracting more competent teachers to teach in them. This allows school students to make choices that better meet their needs. Schools in small settlements often do not have either a sufficient number of students or qualified personnel to provide high school students with in-depth training in the disciplines they are interested in.

Conducting career guidance activities in-school and out-of-school format is a more common and universal practice compared to specialized training. At the same time, regional institutions of higher and secondary vocational education, interested in attracting applicants, actively interact, not only with schools in large cities but also with educational organizations of district centers. Recently, the development of Internet technologies has increased the number of joint events held in an online format, which has increased their accessibility for students from small towns and villages.

In general, according to Russian studies, career guidance activities of schools do not meet the increasing needs of high school students in professional selfdetermination and the choice of further educational trajectory. Traditional forms of work, such as career guidance testing, do not help, according to schoolchildren, to decide on a future profession [14].

In 2020, a significant factor that influenced the choice of educational trajectories of school graduates was the COVID-19 pandemic, which disrupted the sustainable development of all spheres of society, including the education system. The students of the final grade found themselves in the most difficult situation when the problems of switching to the distance learning mode and adapting to the conditions of self-isolation were added to the current tasks of preparing for the Unified State Exam. In this situation, it was necessary not only to graduate safely from school but also to choose a place to continue studying or work. Many previously made career decisions had to be reconsidered, to make a new informed choice, or to postpone it for a certain period, in the hope of changing the situation for the better [15]. The pandemic has acted both as a cause and as a catalyst for other processes that increase educational inequality. So, on the one hand, the gap between urban and rural territories within countries has increased, on the other hand, children from more and less well-off families have found themselves in conditions of different access to opportunities for mastering academic disciplines remotely. It is primarily about the availability of the necessary computer equipment and the ability to connect to the high-speed Internet [16]. Also, among the difficulties of introducing distance learning, which increases social stratification and inequality, mention is made of the difficulties of transition to a new format of classes and a drop in motivation, the inclusion of the family in the organization of training, the difficulty of transferring some events to the online environment, the need for additional training of teachers in new teaching methods [17].

Under these conditions, there is a decrease in the level of post-school migration activity while maintaining a positive attitude towards higher education: more and 
more graduates are making a choice in favor of universities in their home region [18]. This can lead to a decrease in the social mobility of applicants from small towns and remote areas, a narrowing of the range of their educational opportunities [19]. Our study [7] of the peculiarities of admission to a regional university in the context of a pandemic has shown that a significant part of those admitted is young people living in cities of the regional level or district centers, whose families have an average income. At the same time, the influence of the pandemic as a factor that seriously influenced admission was noted, first of all, by first-year students with unformed professional plans.

\section{MATERIALS AND METHODS}

\subsection{Purpose}

The purpose of the study was to establish what impact the territorial factor has on the applicants when entering a university in a Covid-19 pandemic.

Research questions: What are the territorial and socio-economic characteristics of students enrolled in a teacher training program?

Are there any peculiarities of professional selfdetermination among students from the regional center and small settlements? Do the forms of career guidance work differ in schools of different territories?

Are there differences in the transition to a distancelearning format and preparation for the Unified State Exam in schools of the regional center and small settlements? Have they influenced the educational trajectories of graduates?

\subsection{Research Methods}

We used a survey as a method of collecting information. We have developed a questionnaire consisting of two parts. The first section made it possible to collect information about the professional plans of the respondents, the factors that influenced their formation, the motivation of entering the teacher training program. Another section of the questionnaire contained questions about the impact of the pandemic and the conditions of distance learning on school performance, preparation for the Unified State Exam and their results, and, accordingly, on changing plans for entering a university.

In addition, we used the diagnostic test of personal competencies, important for career self-determination, developed by Kovalevskaya [20]. Identification of the level of development of personal characteristics of students is an important indicator of awareness of professional choice and readiness for self-development. This technique, based on the definition of knowledge, skills, and experience related to various aspects of personal and career development, allows us to determine the level of development of 4 competencies of career selfdetermination: the ability and readiness to integrate personal and social interests in professional activity $(\mathrm{C} 1)$, the ability and readiness for professional interaction, and the solution of socially significant tasks $(\mathrm{C} 2)$, the ability and readiness for cognitive reflection $(\mathrm{C} 3)$, the ability and readiness to plan their career and professional future (C4).

\subsection{Participants}

The study involved 97 first-year undergraduate students of the Faculty of Philology of Smolensk State University, studying in the teacher training program, which is $44 \%$ of all those enrolled in this program in the University. All respondents graduated from school and entered the university in the conditions of the COVID-19 pandemic in 2020.

The social context of the study: the distribution of the population of the Smolensk region by territories of different types: $35 \%$ of the population lives in the regional center, $38 \%$ - in small towns, $27 \%$ - in rural areas. The Smolensk region belongs to regions with strong migration sentiments: the proximity of the Moscow region - the largest center of higher education in Russia, orients many school graduates to prepare for admission to the Moscow universities. This is especially true for students of schools of the regional center with high Unified State Exam scores. The Smolensk State University belongs to mass-demand universities offering a wide range of educational programs designed primarily for students from the Smolensk region.

\section{RESULTS AND DISCUSSION}

According to the results of the survey, the subjects were divided into two groups according to their place of residence: those who live in a large city - regional center (the first group: 55 students - 56.7\%) and those who came from a small settlement: from urban district centers - 34 students and rural areas - 8 students (the second group: $43.3 \%$ in total). Obviously, those who came from urban areas quantitatively outnumber those who live in rural areas, which make it possible to consider the territorial factor as one of the essential aspects influencing the choice of the place of obtaining vocational education.

A comparison of the socio-demographic characteristics of the respondents (Table 1) shows the absence of significant gender differences between the two groups. At the same time, the ratio of female and male studying in the teacher training program is generally consistent with the perception of the teacher's profession as predominantly female, and only slightly differs from the actual gender proportion in school. According to our study [21], of the 8,021 school teachers working in the general education in Smolensk region, 7,215 (89.95\%) are female and only $806(10.05 \%)$ are male. 
Table 1. Socio-demographic characteristics of the respondents

\begin{tabular}{|l|c|c|c|c|}
\hline Styles & \multicolumn{2}{|c|}{ G1 $(\mathrm{n}=55)$} & \multicolumn{2}{c|}{$\mathrm{G}$ ( $(\mathrm{n}=42)$} \\
\hline Gender: & & & & \\
female & 47 & 85.5 & 35 & 83.3 \\
male & 8 & 14,5 & 7 & 16.7 \\
\hline Financial situation of the family: & & & & \\
Wealthy, can afford a paid training & 8 & 14.5 & 3 & 7.1 \\
Average income & 35 & 63.6 & 29 & 69.0 \\
The lower-middle-income & 9 & 16.4 & 5 & 11.9 \\
\hline The low income & 2 & 3.5 & 4 & 9.5 \\
\hline Education: & 27 & 49.1 & & \\
free-based & 28 & 50,9 & 20 & 47.6 \\
fee-based & & 22 & 52.4 \\
\hline
\end{tabular}

An important parameter of our research is the level of the financial situation of families of students. In both groups studied, about two-thirds of the respondents assessed family income as average. However, in the group from the regional center, there is a greater spread of opinions, both in the direction of wealth above average and below average compared to the group living in small settlements. The second group is characterized by a significantly smaller number of respondents with high incomes and, in general, a greater bias towards income below average and low income. The data obtained confirm the differences in living standards due to inequality of opportunities in large and small settlements. At the same time, the ratio of free-based education students and fee-based education is approximately the same in both groups. It is obvious that half of the respondents are ready to pay for their education on their own, despite the low material capabilities of their families, which confirms the value of higher education and its importance as a social lift. This idea is supported by other research results. The answers to a number of questions in the questionnaire confirm the motivated choice of the future profession by the majority of students: more than half of the respondents from both groups (56.4\% and $54.8 \%$, respectively) consciously chose the teaching profession in the senior grades when planning their future. Also, students living in small settlements more often noted that they were interested in this profession from childhood $(21.4 \%$ versus $14.5 \%$ of students from the regional center). Perhaps this is due to the smaller choice of professions and the conservative way of life, characteristic of their places of residence. At the same time, for $29 \%$ of students from a large city and $23.8 \%$ from small settlements, the choice of an educational institution turned out to be accidental and was due to the prevailing circumstances.

Answers to questions about career guidance activities of schools showed differences in the possibilities of organizing specialized training in schools of different territories. Thus, $60 \%$ of respondents from the regional center are graduates of humanitarian or socio-economic classes, only $30.9 \%$ of respondents studied in a class with a universal profile. The situation is reversed in the second group, where $66.7 \%$ of students indicated that they graduated from a class with a universal profile and only $23.8 \%$ had the opportunity to gain knowledge in the humanities or socio-economic profile classes. Despite this situation, the responses of students from small settlements indicate participation in a larger number of career guidance events: meetings with representatives of universities and colleges $(61.9 \%)$, psychological testing $(59.5 \%)$, the presence of a special subject "career guidance" $(38.1 \%)$, conversations with teachers about choosing a profession $(31 \%)$, excursions to various enterprises $(28.6 \%)$. Graduates from the regional center also mention similar events in their answers, but much less often: psychological testing (56.4\%), meetings with representatives of universities and colleges $(45.5 \%)$ are most often found in the answers, less than $20 \%$ mention the remaining events. The data obtained may indicate both greater activity in the organization of career guidance activities on the part of schools in small settlements, and a higher motivation for the participation of schoolchildren themselves in them. The latter argument is also confirmed by the results of the answers to the question about the independent activity of students in matters of their professional future. As schoolchildren, respondents from both groups discussed with their parents the issues of choosing a future profession $(61.8 \%$ and $69 \%$, respectively), searched for information about educational programs on university websites $(49.1 \%$ and $47.6 \%$ ). At the same time, the higher interest of schoolchildren living in small settlements is confirmed by more frequent access to specialized sites with educational resources $(47.6 \%$ vs. $29.1 \%$ in the first group), as well as more active attendance of career guidance events at universities $(45.2 \%$ vs. $27.3 \%$ in the first group). Also, respondents from the second group were much more likely to indicate the website and social networks of the educational institution as sources of information about the university and the field of training ( $97.6 \%$ vs. $74.6 \%$ in the first group). Thus, students from small settlements are distinguished by a stronger motivation for admission to university and active actions taken. 
A special aspect of our research was the consideration of the process of admission to the university under quarantine and the transition to distance learning caused by the COVID-19 pandemic, which we consider an external factor that created additional obstacles to the realization of the goals of graduates. When asked about the difficulties associated with the transition to a distance learning format, respondents living in small settlements more often than those living in the regional center noted a significant increase in homework assignments in subjects $(69 \%)$ and a lack of teacher explanations $(59.5 \%)$. In addition, they more often mentioned problems related to changing the daily routine $(35.7 \%)$. Only $12.7 \%$ of respondents from the regional center and $14.3 \%$ from small towns and rural areas noted problems related to the shortcomings of equipment (absence or technical non-compliance with training requirements). These data correlate with the indicators of the material well-being of families obtained above. Separately, it should be noted that graduates from the second group had problems with the Internet connection much more often ( $28.6 \%$ vs. $10.9 \%$ in the first group). Only $16.7 \%$ of respondents from the second group easily adapted to the new changes compared to $25.5 \%$ from the first. Such a change in the educational process could not but affect the academic performance and the results of the Unified State Exam, which was confirmed in the results of the survey. The responses of many respondents clearly show a tendency to improve academic performance both in general and in individual subjects: $56.3 \%$ of students from the first group and $40.4 \%$ of students from the second group. These data, in our opinion, rather indicate the complexity and imperfection of the teachers' organization of control over the assimilation of students' knowledge, the predominance of written assignments and a decrease in contact work. However, even in such a situation, respondents from the second group were twice as likely to note cases of a decrease in academic performance (19\% versus $11 \%$ in the first group). Also, respondents of this group more often mentioned such difficulties in preparing for the Unified State Exam as a decrease in teacher explanations $(40.5 \%)$ and a decrease in preparation time $(28.6 \%)$. However, more than $40 \%$ of respondents from both groups, despite the changed circumstances, tried to devote as much time as possible to preparing for the Unified State Exam. Not everyone was satisfied with the results of the Unified State Exam: $52.7 \%$ of students from the first group and $42.8 \%$ from the second received lower scores than expected for all the Unified State Exam or individual subjects. Due to various reasons, some graduates were forced to change their plans: thus, $14.5 \%$ of the respondents from the first group and $4.8 \%$ from the second did not go to study in another city or region due to the pandemic; and $10.9 \%$ and $21.4 \%$ noted insufficient number of points on the Unified State Exam as reasons for adjusting admission plans. However, it should be noted that almost three quarters of the respondents from both groups did not change their plans and entered the university where they were originally going. At the same time, respondents rather highly appreciated the transition to an online admission system: about half of the respondents from both groups noted the convenience of submitting documents without having to come in person, as well as greater efficiency in tracking ratings. As the main drawback, students from small settlements more often than residents of the regional center called technical difficulties in the work of the personal account $(45.2 \%$ vs. $32.7 \%)$.

The results of diagnostics of the level of development of personal competencies significant for career selfdetermination are presented in Table 2.

Table 2. Comparison of indicators of personal competencies those are important for career selfdetermination.

\begin{tabular}{|c|c|c|}
\hline \multirow{2}{*}{ Factor } & \multicolumn{2}{|c|}{ Average value } \\
\cline { 2 - 3 } & G1 & G2 \\
\hline C1 & 7.75 & 7.64 \\
\hline C2 & 7.48 & 7.35 \\
\hline C3 & 8.25 & 8.10 \\
\hline C4 & 7.79 & 7.69 \\
\hline
\end{tabular}

As can be seen from the presented data, on average, respondents of both groups have fairly high and very similar indicators for all competencies, which indicate that the territorial factor does not hinder the development of personal characteristics, if there is a formed motivation for professional choice.

\section{CONCLUSIONS}

The analysis of the socio-demographic characteristics of the studied students shows the influence of the territorial factor of the place of residence on admission to the university: the percentage of applicants from small towns and rural settlements $(43.3 \%)$ is less than the total percentage of the population living outside the regional center $(65 \%)$.

At the same time, with the overall high motivation for admission to the chosen education program it can be stated that students who came from small settlements more often consciously chose the profession of a teacher. This is confirmed by the data of the diagnostic study, which found no differences in the indicators of personal competencies significant for career self-determination among students on a territorial basis. Students from small localities, despite the limited opportunities to study in specialized classes, compared with students from the regional center, were more active in participating in various career guidance events, searching for information for admission on Internet resources, and also more often discussed their professional plans with their parents. Despite the fact that this group of students adapted more difficult to the conditions of distance learning during the COVID-19 pandemic, more often experiencing 
methodological and technical difficulties, they passed the Unified State Exam more confidently, and most of them entered the previously chosen specialty.

\section{REFERENCES}

[1] I.G. Grunicheva, M.A. Pinskaya, S.G. Kosaretsky, Support of schools with bad learning outcomes as part of the national educational policy. In: Survey of world experience, Educational Studies Moscow, 3 (2012) pp. 30-63.

[2] Over the barriers: Stories of schools operating in difficult social conditions, M.A. Pinskaya, S.G. Kosaretsky (Eds) (2019).

[3] M. K. Ali, Analysis of enrollment: A spatialinteraction model. In: Journal of Economic Insight, 29(2) (2003) pp. 67-86.

[4] I. Prakhov, The barriers of access to selective universities in Russia. In: Higher Education Quarterly, 70(2) (2016) pp. 170-199.

[5] R.I. Kapelyushnikov, Return on education in Russia: nowhere lower? (2021).

[6] S. S. Malinovskiy, E. Yu. Shibanova, Regional Differentiation of Access to Higher Education in Russia, (2020).

[7] F Kremen, S. Kremen, Features of career selfdetermination of regional university applicants in the context of the COVID-19 pandemic. In: E3S Web of Conferences, 291 (2021). DOI: https://doi.org/10.1051/e3sconf/202129105020.

[8] The average score of applicants to pedagogical universities in Russia has increased. In: TASS, Russian News Agency (2021). https://tass.ru/obschestvo/12133541.

[9] F. M. Kremen, S. A. Kremen, Teacher as a role model in the professional self-determination of schoolchildren. In: Journal of pedagogic research, 2(6) (2017) pp. 13-21.

[10] F. Kremen, S. Kremen, Development of Vocational Guidance in the Education System as a Factor of Social Justice in the Conditions of Contemporary Challenges: A Comparative Study. In: ARPHA Proceedings, 3, pp. 1277-1289. DOI: https://doi.org/10.3897/ap.2.e1277.

[11] C. Buzzi, M. Tucci, R. Ciprandi et all., The psychosocial effects of COVID-19 on Italian adolescents' attitudes and behaviors. In: Italian Journal of Pediatrics, 46((1)(69)) (2020). DOI: https://doi.org/10.1186/s13052-020-00833-4.

[12] S. Whiteley, Youth at risk: why don't they just enroll in a tertiary course or get a job? In: Journal Youth Studies Australia, 20(2) pp. 23-28.
[13] (Non)ordinary schools: diversity and inequality, M. Carnoy, G. S. Larina, V. M.Markina (Eds) (2019).

[14] S. G. Kosaretsky, K. A. Barannikov, A. A. Belikov et all., The Russian school: the beginning of the XXI century (2019).

[15] S. Kremen, K. Tsitsikashvili. The representations of the regional university students about the "gap year" in conditions of the Covid-19 pandemic. In: E3S Web of Conferences, 296 (2021) 08008. DOI: https://doi.org/10.1051/e3sconf/202129608008.

[16] "Black Swan" in a white mask - HSE analytical report on the anniversary of the COVID-19 pandemic, S. M. Plaksin, A. B. Zhulin, S. A. Farizova (Eds) (2021).

[17] N. K. Radina, Ju. V Balakina, Challenges for Education during the Pandemic: An Overview of Literature. In: Educational Studies Moscow, 1 (2021) pp. 178-194. DOI: https://doi.org/10.17323/1814-9545-2021-1-178194.

[18] M. N. Artemenkov, E. E. Sukhova, Transformation of school graduates' educational strategies in the context of coronavirus covid-19: regional dimension. In: Regional Research., 2(68) (2020) pp. 111-120.

[19] V. Koksharov, D. Sandler, P. Kuznetsov et all., The Pandemic as a Challenge to the Development of University Networks in Russia: Differentiation or Collaboration? In: Educational Studies Moscow, 1 (2021) pp. 52-73. DOI: https://doi.org/10.17323/1814-9545-2021-1-52-73.

[20] E.V. Kovalevskaya, Early Career SelfDetermination: Structural and Content Characterisation and Formation (2015).

[21] F. Kremen, S. Kremen, The Influence Of Gender Leadership Styles Of Teachers On The Professional Choice. In: EdCW 2020, EpSBS, 114 (2021) pp. 94-103.

DOI: doi.org/10.15405/epsbs.2021.07.02.12. 